EDITOR'S

- An additional table is published online only. To view this file please visit the journa online (http://tobaccocontrol. bmj.com).

\section{Correspondence to} David Hammond, Department of Health Studies and Gerontology, University of Waterloo, 200 University Avenue West, Waterloo, Ontario, N2L 3G1, Canada;

dhammond@uwaterloo.ca

Received 29 April 2010 Accepted 8 March 2011 Published Online First 23 May 2011

\title{
Health warning messages on tobacco products: a review
}

\author{
David Hammond
}

\section{ABSTRACT}

Objective To review evidence on the impact of health warning messages on tobacco packages.

Data sources Articles were identified through electronic databases of published articles, as well as relevant 'grey' literature using the following keywords: health warning, health message, health communication, label and labelling in conjunction with at least one of the following terms: smoking, tobacco, cigarette, product, package and pack. Study selection and data extraction: Relevant articles available prior to January 2011 were screened for six methodological criteria. A total of 94 original original articles met inclusion criteria, including 72 quantitative studies, 16 qualitative studies, 5 studies with both qualitative and qualitative components, and 1 review paper: Canada $(n=35)$, USA $(n=29)$ Australia $(n=16)$, UK $(n=13)$, The Netherlands $(n=3)$, France $(n=3)$, New Zealand $(n=3)$, Mexico $(n=3)$, Brazil $(n=2)$, Belgium $(n=1)$, other European countries $(n=10)$, Norway $(n=1)$, Malaysia $(n=1)$ and China $(n=1)$.

Results The evidence indicates that the impact of health warnings depends upon their size and design: whereas obscure text-only warnings appear to have little impact, prominent health warnings on the face of packages serve as a prominent source of health information for smokers and non-smokers, can increase health knowledge and perceptions of risk and can promote smoking cessation. The evidence also indicates that comprehensive warnings are effective among youth and may help to prevent smoking initiation. Pictorial health warnings that elicit strong emotional reactions are significantly more effective. Conclusions Health warnings on packages are among the most direct and prominent means of communicating with smokers. Larger warnings with pictures are significantly more effective than smaller, text-only messages.

\section{INTRODUCTION}

Tobacco use is responsible for one in ten global deaths and is the second major cause of mortality in the world. ${ }^{1}$ In 2009 , more than 5 million people died from tobacco use, more than tuberculosis, HIV/AIDS and malaria combined. ${ }^{2}$ The health burden from tobacco reflects the wide range of smoking-related diseases: causal links have been identified for 10 types of cancer as well as 18 other diseases. ${ }^{3}$ Remarkably, the list of known health risks continues to grow, with cancers of the stomach and acute myeloid leukaemia among those most recently identified.

Health warnings on tobacco packages have emerged as an important medium for communicating the health risks of tobacco use to consumers. Tobacco packages provide high reach and frequency of exposure-pack-a-day smokers are potentially exposed to the warnings over 7000 times per year-as well as an opportunity to communicate with smokers during the act of smoking. ${ }^{45}$ Tobacco packs also serve as portable advertisements with high levels of exposure among non-smokers: unlike many other consumer products, cigarette packs are displayed each time the product is used and are often left in public view between uses. ${ }^{6}$ Tobacco packages are also prominent in retail outlets, where product displays are common and typically increase in prominence as other forms of tobacco marketing are restricted.

International guidelines for cigarette health warnings have been established under Article 11 of the WHO's Framework Convention on Tobacco Control (FCTC) - the first international treaty devoted to public health. ${ }^{8}$ The FCTC requires rotating health warnings that cover at least $30 \%$ of the front and back of cigarette packages. Beyond these minimum requirements, the FCTC states that warnings 'should' cover $50 \%$ or more of a package's principal surfaces, and 'may' include pictures. 'Elaborated guidelines' include additional information to help guide implementation with more detailed recommendations, including general design, position and the content of warnings. ${ }^{9}$ To date, more than 165 countries have ratified the treaty.

At present, cigarette packages in the vast majority of countries carry a health warning; however, the position, size and general strength of these warnings vary considerably across jurisdictions. ${ }^{10}{ }^{11}$ In 2001 , Canada became the first country in the world to implement pictorial warnings and set new precedents in terms of the size of warnings, which covered $50 \%$ of the principal display areas (see figure 1 ). More than 30 countries have since adopted the FCTC recommendation for pictorial warnings that cover at least half of the package. ${ }^{11} \mathrm{New}$ precedents continue to be set in terms of the size of warnings; in Uruguay, for example, health warnings cover $80 \%$ of the front and back of packages.

Scientific literature on the impact of tobacco health warnings has grown in parallel with changes in regulatory practice. The current paper seeks to review evidence on the effectiveness of health warnings on tobacco packages. More specifically, the study sought to review evidence on the following: (1) differences between text versus pictorial warnings, (2) impact on youth and adults, (3) impact of message content and themes and (4) impact on cessation behaviour, including any potential adverse outcomes.

\section{METHODS}

Published articles were identified through electronic searches of MEDLINE (Medical Literature Analysis 

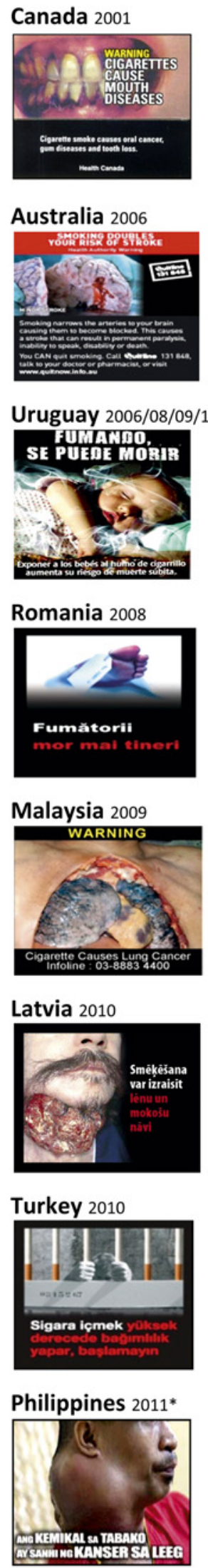
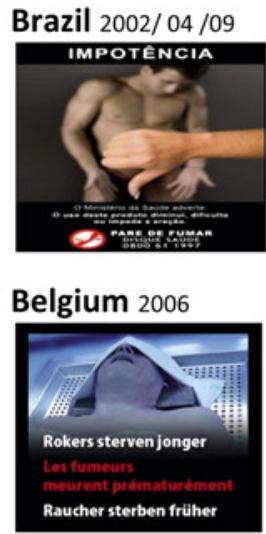

Hong Kong 2007
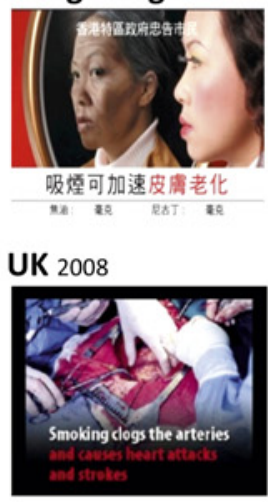

\section{Mauritius 2009}

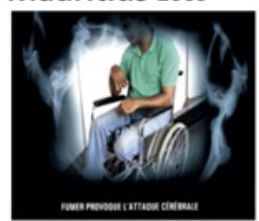

Mexico 2010

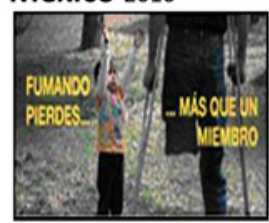

France 2011

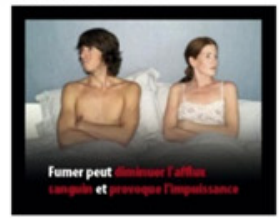

Urkraine 2012*

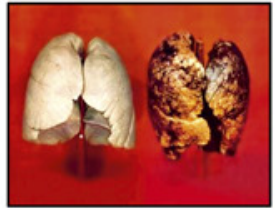

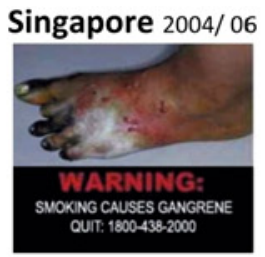

Chile 2006/07/08/09/10

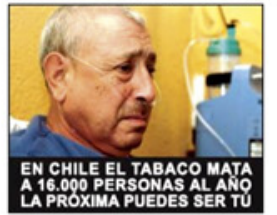

Brunei 2008

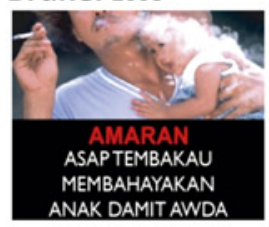

Djibouti 2009

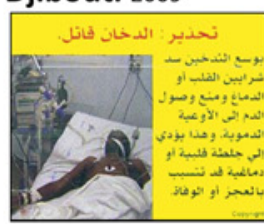

Peru 2009

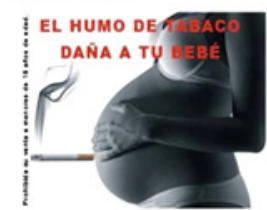

Mongolia 2010

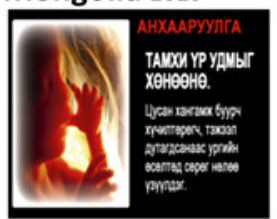

Malta 2011

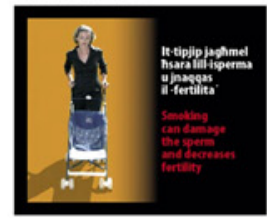

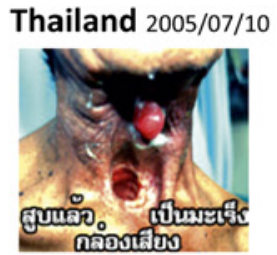

Jordan 2006

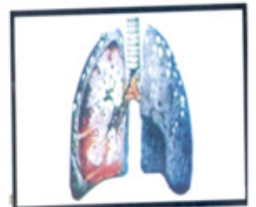

Egypt 2008/10

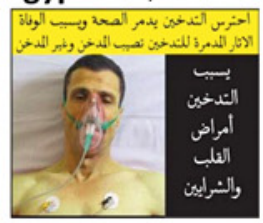

India 2009/11

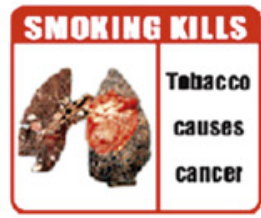

Taiwan 2009

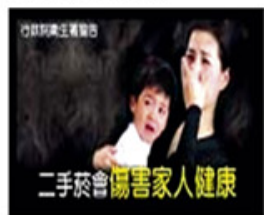

Pakistan 2010

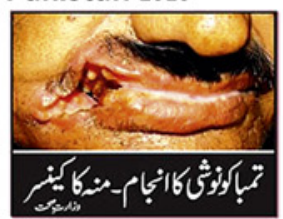

Spain 2011*

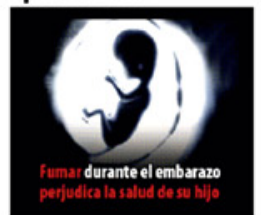

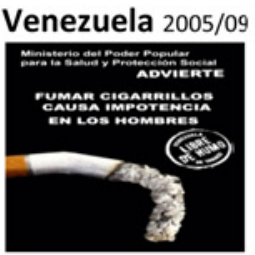

Panama 2006/09

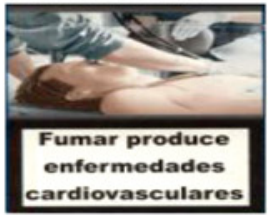

New Zealand 2008

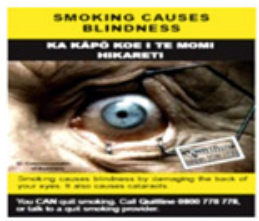

Iran 2009

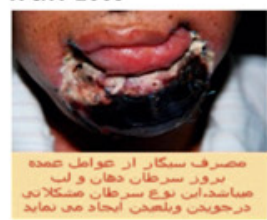

Colombia 2010

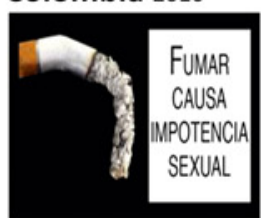

Switzerland 2010

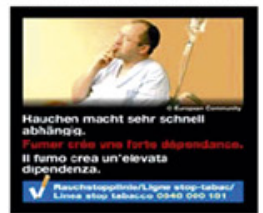

Norway 2011*

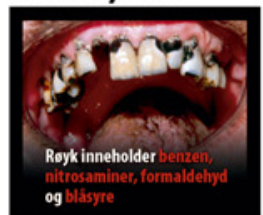

*Proposed implementation date at time of publication.

Figure 1 Pictorial health warnings and implementation dates. 
and Retrieval System Online) and Web of Science databases. Electronic searches were also conducted to identify relevant 'grey literature', including unpublished research commissioned by governments. Additional searches using the reference lists of relevant articles were also conducted. The following keywords were used to identify relevant articles: health warning, health message, health communication, label and labelling in conjunction with at least one of the following terms: smoking, tobacco, cigarette, product, package and pack. The review was limited to articles that reported original research findings and were available for review by December 2010. Studies examining health warnings on advertisements (rather than packages) were excluded, as were studies on other aspects of packaging and labelling regulations, including labelling of ingredient and 'constituent' information as well as restrictions on deceptive marketing practices. Due to the diversity of research methods in this domain, we did not restrict studies to a particular design; however, each of the articles were reviewed for the following methodological criteria: (1) clearly stated objective/research question, (2) clear description of sample/study population, (3) consistent data collection method, (4) key measures appear to be valid, (5) main outcomes are defined and measurable and (6) analysis and summary of findings are clear and appropriate. Each article was reviewed by two independent reviewers. A total of 103 papers presenting empirical data were identified that met the general eligibility criteria. Following review of the full-text articles, seven were excluded on the basis of insufficient methodological information. The 94 original articles included in the review consisted of 72 quantitative studies, 16 qualitative studies, 5 studies with both qualitative and qualitative components, and 1 review paper. A summary of each study is available in online supplementary table 1 . Research articles came from the following jurisdictions: Canada $(n=35)$, USA $(n=29)$ Australia $(n=16)$, UK $(n=13)$, The Netherlands $(n=3)$, France $(n=3)$, New Zealand $(n=3)$, Mexico $(n=3)$, Brazil $(n=2)$, Belgium $(n=1)$, other European countries $(n=10)$, Norway $(n=1)$, Malaysia $(n=1)$ and China $(n=1)$. Note that several articles included data collected in multiple countries: these articles were counted as a single study but recorded in multiple jurisdictions.

\section{RESULTS}

\section{General awareness and prominence of health warnings}

Smokers report high levels of awareness for health warnings on tobacco packages. ${ }^{12-25}$ Data collected from a series of cohort studies found that more smokers reported getting information about the risks of smoking from cigarette packages than from any other source except television in a majority of countries. ${ }^{26}$ For example, in countries with large pictorial warnings, such as Thailand, Australia and Uruguay, more than $85 \%$ of smokers cited packages as a source of health information. ${ }^{26}$ A notable exception is the low levels of salience for more obscure warnings that appear on the side of packages, such as the health warnings implemented in the USA in $1984 .{ }^{27} 28$ The findings suggest that small text warnings are associated with low levels of awareness and poor recall. ${ }^{29}$

Health warnings have also been found to be a prominent source of health information for non-smokers and the general public. ${ }^{14-172124}$ For example, 86\% of non-smokers in Canada agreed in a national survey that the warnings on cigarette packs provide them with important health information. ${ }^{15}$ Nonsmokers also report high levels of recall for specific health messages on packs. ${ }^{17}$ For example, more than a third of adult non-smokers in Australia could recall at least one specific pictorial warning on cigarette packs in a 2008 survey. ${ }^{24}$ In the UK, a national survey of youth conducted in 2008 found that approximately $60 \%$ of non-smokers could recall a specific warning displayed on the front of UK packs. ${ }^{16}$

The salience of health warnings depends upon the size and position of the warning message. Youth and adults are more likely to recall larger warnings, rate larger warnings as having greater impact, and often equate the size of the warning with the magnitude of the risk. ${ }^{18} 1924{ }^{30-34}$ For example, a recent experimental research study conducted in Canada found that increasing the size of pictorial warnings from the current size of $50 \%$ of the principal display area to $75 \%, 90 \%$ and $100 \%$ enhanced their impact among adult smokers, youth smokers, as well as 'vulnerable' youth non-smokers. ${ }^{19} 20$ A recent study conducted in Australia, where pictorial warnings cover $90 \%$ of the front and $30 \%$ of the back of packs, also found that the effectiveness of warnings could be improved by increasing the size of the warnings further. ${ }^{24}$

Features that distinguish the warning messages from the package design have also been found to increase the impact of health warnings. Using a box or perimeter around the outside of the message has been found to increase the salience and recall of warnings, ${ }^{30}$ while contrasting colours, such as black lettering on a white background, are the easiest to read and increase comprehension. ${ }^{3135}$

\section{Impact of text warning labels on health beliefs and attitudes}

Several studies have shown that large text-based warnings are associated with increased perceptions of risk and health knowledge. ${ }^{12}$ Cross-sectional surveys conducted in Canada during the 1990s found that the majority of smokers reported that package warning labels were an important source of health information and had increased their awareness of the risks of smoking. ${ }^{15} 182136$ An Australian study ${ }^{22}$ found that, relative to non-smokers, smokers demonstrated an increase in their knowledge of the main constituents of tobacco smoke and identified significantly more disease groups following the introduction of new Australian warning labels in 1995.

Several studies have also evaluated the enhancement of text warnings in the European Union (EU). In 2003, EU warnings were required to be a minimum of $30 \%$ of the 'front' and $40 \%$ of the 'back' of packs. A series of 52 focus groups conducted in seven European countries in 2004 found that the enhanced text warnings in the EU were more noticeable than smaller warnings printed previously on packs, with a greater potential to help smokers to quit (figure 2) ${ }^{37}$ A cohort study conducted in the UK before and after the enhanced warnings were implemented also found that the salience of the warnings increased dramatically among UK smokers, along with the frequency of thoughts regarding health effects and level of health knowledge. ${ }^{27}$ These findings are consistent with a number of population-based surveys conducted after the implementation of the enhanced warnings in France, ${ }^{38}$ Scotland and Ireland, ${ }^{39}$ Spain $^{40}$ and Belgium. ${ }^{41}$ Collectively, these studies indicate that smokers' awareness of the warnings increased following implementation of the new warnings and a considerable proportion of smokers reported measures consistent with increased perception of health risks as a result of more comprehensive text warnings.

Impact of pictorial warning labels on health beliefs and attitudes A wide variety of research has demonstrated the effectiveness of using pictures and imagery in health communications. ${ }^{42-50}$ These studies suggest that health warnings with pictures are significantly more likely to draw attention, result in greater 


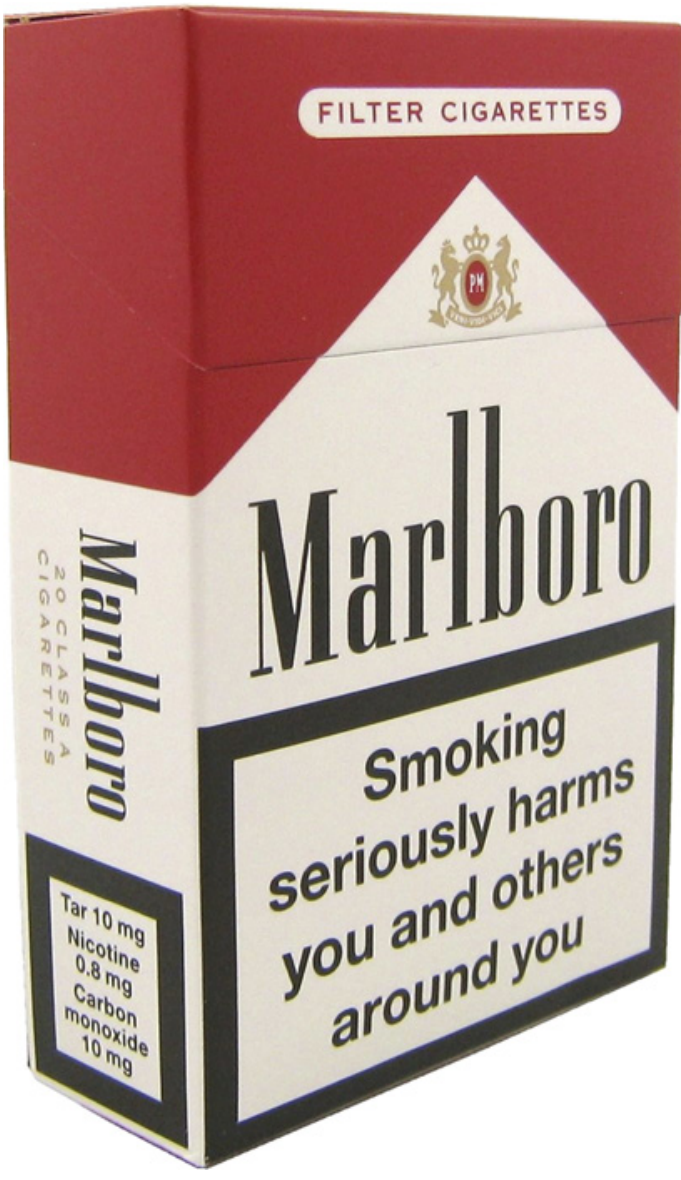

Figure 2 An example of EC/UK text-only warnings (2003).

information processing and improve memory for the health message.

Experimental research on cigarette warnings has also found that picture-based warnings are more likely to be rated as effective than text-only warnings on a range of outcomes, including as a deterrent for new smokers and a means to increase cessation among current smokers. ${ }^{51-56}$ For example, a 2008 study conducted in China found that smokers were significantly more likely to rate pictorial warnings as more effective than text warnings for motivating smoking cessation and for preventing smoking among youth. ${ }^{57}$

Extensive focus group testing and market research commissioned by government health agencies also support the effectiveness of pictorial health warnings on packages. ${ }^{30} 415358-67$ This research consistently demonstrates that health warnings with pictures are rated by smokers and non-smokers as more effective than text-only warnings. For example, a set of 40 focus groups conducted in Canada approximately 5 years after the introduction of pictorial warnings concluded that: 'The picture was generally the first thing people looked at and related to. It determined the strength of the warning's emotional impact and noticeability. For many participants, the picture played the key role in understanding the message, and tended to override the meaning conveyed by the words in the headline.'(p 26) ${ }^{67}$ A series of 24 focus groups conducted in Australia approximately 2 years after the introduction of the pictorial warnings came to similar conclusions: 'Throughout the group discussions the graphic health warnings were invariably considered to have greater impact than the previous text-only health warnings... The graphic images have seemingly increased or reinforced awareness of those consequences that were previously text only... as well as, communicated new information'(pp 12-16) (figure 3). ${ }^{62}$

Since 2001, when Canada became the first country to implement pictorial health warnings on cigarette packs, a series of population-based surveys have compared the effectiveness of text versus pictorial warnings. These findings are consistent with both experimental studies and government-commissioned research: pictorial warnings are more likely to be noticed and read by smokers, are associated with stronger beliefs about the health risks of smoking, as well as increased motivation to quit smoking. $^{23} 2627515255$ 58-62 67-74

Picture warnings also appear to be effective among youth. Approximately 6 years after their introduction, more than $90 \%$ of Canadian youth agreed that picture warnings on Canadian packages had provided them with important information about the health effects of smoking cigarettes, are accurate, and made smoking seem less attractive. ${ }^{21}$ Other national surveys of Canadian youth suggest similar levels of support and selfreported impact. ${ }^{18} \mathrm{~A}$ recent longitudinal evaluation of pictorial warnings among Australian school children found that students were more likely to read, attend to, think about, and talk about health warnings after the pictorial warnings were implemented in 2006. ${ }^{71}$ In addition, experimental and established smokers were more likely to think about quitting and to forgo smoking a cigarette, while intention to smoke was lower among those students who had talked about the warning labels and had forgone cigarettes.

Only three of the studies we identified failed to support the superiority of text over graphic warnings. An experimental study conducted with youth smokers in Germany compared the current EU text warnings with corresponding pictorial warnings, and failed to detect any significant differences between the conditions. ${ }^{75}$ The second study examined the impact of briefly viewing a text versus pictorial warning on a website among 296 non-smoking secondary-school students from Canada and the USA. The study found that the picture warnings were more effective than the text-only warning at lowering intentions to

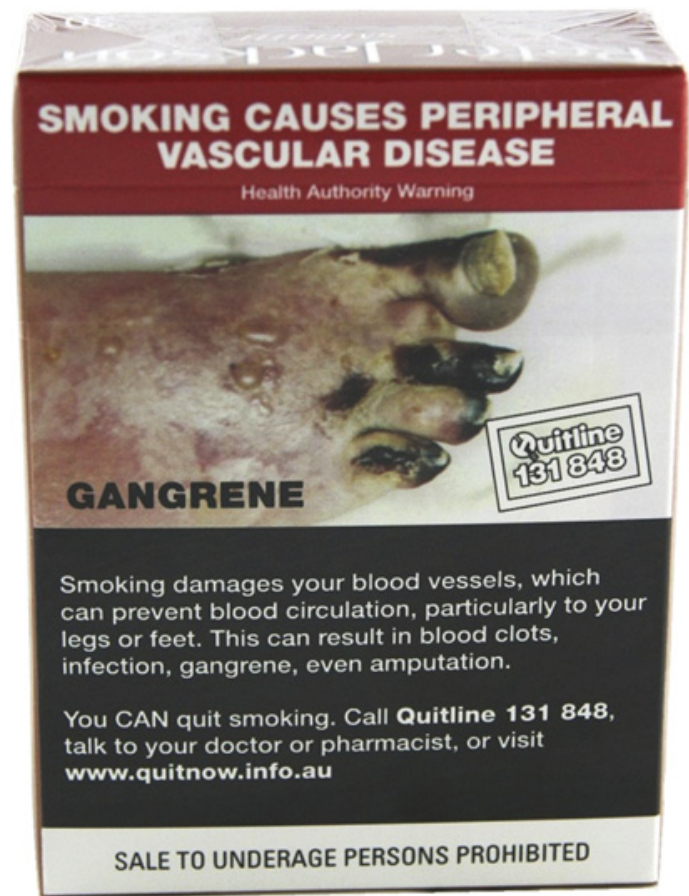

Figure 3 A sample pictorial health warning in Australia (2010). 
smoke among the Canadian students, but less effective among US students. ${ }^{76}$ The third study examined the speed with which participants responded to a text statement (some of which were accompanied by an image) as an outcome, and failed to note differences. ${ }^{77}$ However, as the authors note, measures of reaction time may not be an appropriate measure of the impact of a warning, particularly considering that emotional responses may increase rather than decrease reaction time.

\section{Health warnings and cessation behaviour}

The extent to which health warnings lead to changes in smoking behaviour is difficult to ascertain within the context of population-based data. ${ }^{78}$ However, significant proportions of adult and youth smokers report that large text and pictorial health warnings have reduced their consumption levels, increased their likelihood of quitting, increased their motivation to quit and increased the likelihood of remaining abstinent following a quit attempt. ${ }^{15} 1821-27686979-82$ For example, onefifth of smokers in an EU-wide survey reported that health warnings have been effective in getting them to smoke less and in helping them try to quit. ${ }^{17}$ In countries with pictorial health warnings, such as Canada and Australia, these numbers are higher: more than $40 \%$ of Canadian smokers report that the pictorial warnings have motivated them to quit smoking ${ }^{68}$; in Australia, $57 \%$ of smokers report that the labels have made them think about quitting and $34 \%$ say the warnings have helped them to try to quit. ${ }^{24}$ Similar findings have been observed among youth. For example, in 2008, almost $80 \%$ of youth smokers in the UK agreed that the warnings had 'put me off smoking'. ${ }^{16}$ Three longitudinal studies-two with adults and one with youth-found an association between reading and thinking about health warnings and subsequent cessation behaviour, including a cohort study conducted with nationally representative samples of smokers in Canada, Australia, the UK and the USA. ${ }^{23} 3971$

Health warnings have also been associated with increased use of effective cessation services. Research conducted in the UK, The Netherlands, Australia and Brazil examined changes in the use of national telephone 'helplines' after the contact information was displayed within package health warnings. Each of these studies reported significant increases in call volumes following the introduction of new warnings. ${ }^{25} 6583-86$ For example, calls to the smoking cessation helpline in The Netherlands increased more than 3.5 times in the 12 months after the helpline number was printed on the back of one of 14 package warnings. ${ }^{84}$ In the UK, call volume increased by as much as 4000 calls per month after the introduction of larger text warnings. ${ }^{83}$

Surveys among former smokers also suggest that health warnings promote long-term abstinence from smoking. In Australia, $62 \%$ of quitters reported in 2008 that the pictorial warnings had 'helped them to give up smoking,' while $75 \%$ reported the warnings 'had an effect on their behaviour'-a significant increase from the $25 \%$ who reported an effect from text warnings 8 years earlier. ${ }^{24}$ In addition, approximately $30 \%$ of former smokers in the EU reported in 2008 that health warnings had helped prevent them from smoking again, ${ }^{17}$ with similar proportions of former smokers in Canada reporting that pictorial health warnings helped them to remain abstinent. ${ }^{87}$

A single study has examined changes in prevalence due to health warnings. The study concluded that the implementation of pictorial warnings in Canada reduced daily consumption of cigarettes, but had no discernable impact on prevalence. ${ }^{88}$ However, there are serious limitations to linking changes in national prevalence and health warnings in this way. First, the study examined prevalence rates in the 6 months following the implementation date of the regulation, which did not correspond to the date when health warnings began appearing on packages. Although warnings are expected to exert their impact over time, the pictorial warnings in Canada took many months to appear in retail outlets and appeared on relatively few packs during much of the follow-up period examined by the study. In fact, the prevalence of adult smoking in Canada has declined approximately $6 \%$ since the implementation of large pictorial warnings in $2001 .^{89}$ However, there is no way to attribute these declines to the new health warnings given that health warnings are typically introduced against a backdrop of other tobacco control measures, including changes in price/taxation, mass media campaigns and smoke-free legislation.

\section{Health warnings and smoking initiation}

A few studies have attempted to directly assess the impact of health warnings on smoking initiation among youth using prevalence rates. Although youth smoking rates have declined dramatically in countries such as Canada after the implementation of large pictorial health warnings, ${ }^{89}$ there is no reliable way to attribute these changes specifically to the warnings rather than other tobacco control measures. However, population-based surveys indicate that significant proportions of youth non-smokers, including the most vulnerable youth populations in Canada, ${ }^{14} 1921$ the $\mathrm{UK}^{16}$ and Australia ${ }^{71}$ report that warnings have discouraged them from smoking. Between one-fifth and two-thirds of youth non-smokers indicated that the warnings had helped prevent them from taking up smoking in Canada ${ }^{21}$ and Australia, ${ }^{24}$ and approximately $90 \%$ of youth non-smokers in a national UK survey reported that the warnings 'put them off smoking. ${ }^{16}$ Longitudinal surveys in Australia also found that experimental and established smokers were more likely to think about quitting and forgo cigarettes after the implementation of large pictorial warnings, while the intention to smoke was lower among those students who had talked about the warning labels. ${ }^{71}$ Finally, nationally representative surveys conducted in 2008 with over 26000 respondents from 27 EU member states and Norway found that 3 out of 10 non-smokers in the EU reported that health warnings were effective in preventing them from smoking. ${ }^{17}$ Levels were highest in Romania, where pictorial warnings were implemented shortly before the survey was conducted, with 6 in 10 non-smokers reporting that the warnings have helped to prevent them from smoking. ${ }^{17}$

Overall, while it is not possible to quantify the impact of health warnings on smoking prevalence, all of the evidence conducted to date suggests that comprehensive health warnings can promote cessation behaviour and discourage initiation, and that larger pictorial warnings are most effective in doing so.

\section{Message theme and content of health warnings}

Health warnings vary considerably in their content and 'executional' style. Qualitative research and pre-market focus group testing have evaluated the content of health warnings in several jurisdictions. The primary outcomes used to evaluate health warnings include their ability to attract attention, comprehension, credibility, novelty, personal identification, and emotional appeal. $^{16} 42596367$ Negative emotions, such as fear, may be particularly important in the effectiveness of large pictorial warnings given the importance of emotional arousal in message acceptance. $^{9091}$ Negative emotional reactions to cigarette health warnings have been associated with increases in key outcomes such as intentions to quit, thinking about health risks or 
engaging in cessation behaviour. ${ }^{55626992}$ For example, a Canadian study found that approximately half of smokers reported at least some fear, disgust or anger in response to the pictorial health, and levels of fear and disgust were associated with an increase in cessation behaviour at follow-up. ${ }^{69}$ An experimental study conducted in the USA found that pictorial warnings were associated with greater negative emotions than US style text warnings, and that these emotions were associated with more negative attitudes towards smoking. ${ }^{92}$ Other negative emotions such as disgust may also play a role in message acceptance for graphic pictorial health warnings, although this has yet to be explored in the context of package warnings. ${ }^{93-95}$

Graphic depictions of disease appear to be the most reliable way to elicit negative emotional reactions to health warnings. ${ }^{37} 4254596162646567697496$ For example, research conducted in Canada with 40 focus groups to test new health warning concepts concluded that:

Participants in all groups consistently expected or wanted to be shocked by HWMs [Health Warning Messages], or emotionally affected in some way. Even if the feelings generated were unpleasant ones to tolerate, such as disgust, fear, sadness or worry, the emotional impact of a warning appeared to predict its ability to inform and/or motivate thoughts of quitting. HWMs which worked on emotions rather than on knowledge or beliefs were often acknowledged as effective and noticeable, and actually motivated thinking. When a strong emotion generated by a HWM was supported by factual information, that was the best combination possible. (p 3$)^{67}$

Studies of the pictorial warnings developed in the European Union also support the effectiveness of fear-arousing health warnings. Studies in France, ${ }^{64}$ Belgium, ${ }^{41}$ Spain, ${ }^{40}$ Bulgaria ${ }^{66}$ and the $\mathrm{UK}^{65}$ consistently demonstrated that warnings with shocking images (such as rotten teeth or throat cancer) were rated as most effective. Shocking images are also most likely to be recalled by smokers in population-based studies of warnings on Canadian, ${ }^{15}{ }^{21}$ Australian $^{24}$ and European ${ }^{41}$ cigarette packs. For example, the top four warnings recalled by Australian smokers and nominated as most effective all depicted graphic health effects, including a picture of a lung cancer tumour, a sick baby in a hospital, a picture of mouth cancer and a gangrenous foot. ${ }^{24}$ Likewise, a series of national surveys also suggest that Canadian smokers and non-smokers are most likely to recall images of rotting lungs and diseased mouths-both graphic depictions of disease-as well as a picture of a limp cigarette depicting impotence. ${ }^{1621}$ However, it is worth noting that at least one study found that recall of health warnings was lower for moderately or highly graphic pictorial warnings compared with controls and warnings with less graphic content. ${ }^{55}$ As the authors of this study point out, health warning recall measured following a single exposure during a study does not replicate 'real world' conditions, in which smokers are repeatedly exposed to warnings.

Warnings that highlight negative aesthetic effects of smoking may be particularly effective among young people. ${ }^{37} 596265$ These messages include those that specifically target health consequences of smoking such as wrinkled skin, premature ageing and skin discolouration, as well as warnings that feature an externally visible health consequences, particularly on highly visible areas such as the face, such as rotting teeth and cancerous gums.

Warnings that depict elements of human sufferingdepictions of personal experience including the social and emotional impact of tobacco use, or consequences for quality of life- have also been found to be effective. In a study conducted among Mexican youth, warnings that depicted elements of human suffering-both to oneself and others-were rated as significantly more effective than warnings without elements of human suffering. ${ }^{97}$ In contrast, warnings that relied on symbolic representations, including imagery or symbols, were significantly less likely to be effective.

The use of 'narratives' or personal testimonials that depict the images and experiences of 'real' people has been associated with increased emotional impact of warnings. ${ }^{98}$ For example, a study conducted in Mexican adults and youth found that adding names and ages of the individuals portrayed in health warnings increased the perceived effectiveness of warnings. ${ }^{97}$ Research also suggests that factual or 'scientific' information can enhance emotionally vivid warnings to maximise message acceptance, particularly when it is written in a clear, direct manner. ${ }^{59} 6799$ These findings underscore the importance of credibility or 'believability' with regards to message acceptance: warnings that appear to be 'staged' or 'fake' undermine a message and lead to message rejection. ${ }^{99}$

Evidence on the impact of positive health warning messages is mixed. Focus groups have consistently reported a desire among smokers for more positive health warning messages, particularly among smokers actively contemplating quitting. ${ }^{37} \quad 58 \quad 59 \quad 63$ However, positive-themed cessation messages are typically rated as having lower impact than fear-appeals or 'graphic' health warnings, and are less likely to be recalled in population-based surveys. $^{37} 5859$ Experimental studies of positive messages are generally consistent with evidence from focus groups. For example, 'gain-framed' messages on packs, which focus on the benefits of quitting, were rated by youth as significantly less likely to reduce tobacco consumption and encourage quitting compared with 'loss-framed' messages. ${ }^{100}$ Despite the lack of evidence supporting the effectiveness of general messages of support, smokers consistently endorse the inclusion of detailed information on the benefits of quitting, as well as concrete information on forms of cessation assistance and tips for quitting. ${ }^{24} 6799$

Finally, focus groups have yielded mixed findings on the impact of addiction-focused messages. Many smokers view these types of messages as 'old' information and several noted that they contribute to a sense of fatalism. ${ }^{62}$ Warnings on addiction may also meet with some resistance from youth and young adults, many of whom do not perceive themselves to be addicted. ${ }^{67}$

\section{Potential adverse outcomes from health warnings}

Graphic, fear-arousing warnings have been criticised on the grounds that they may arouse 'excessive' levels of fear among smokers, leading to defensive reactions such as rejection of the message, avoidance of the warnings or even increases in smoking as an act of defiance. ${ }^{101-106}$ One study conducted among US youth reported an association between increased smoking and increased knowledge of health warnings - a finding characterised by the authors as 'paradoxical' and evidence that US health warnings were ineffective. ${ }^{107}$ However, because exposure to health warnings is 'tied' to exposure of cigarette packs, one might expect such an association during the period of smoking initiation among youth: as the intensity of smoking behaviour increases, so also does the familiarity with packages. Without a comparison group, the authors had no way of knowing whether the increases in smoking behaviour were greater, less or no different than would have been the case if no warnings or more comprehensive warnings had been implemented.

In contrast to the findings of this study, no significant adverse outcomes have been noted in the other quantitative or 
qualitative studies included in this review. Population-based surveys have recorded significant avoidant behaviours among smokers, in terms of efforts to hide the warnings using a case or trying to avoid a particular warning at the point-of-sale; however, in the same studies, smokers who reported avoidance behaviour were just as likely as others to subsequently attempt to quit smoking and report benefits from health warnings. ${ }^{39}$ In the context of the warning labels, avoidance behaviour might be more reasonably interpreted as a measure of effectiveness: if the warnings were ineffective in communicating the threatening consequences of smoking there would be no reason to avoid them

One possible reason for the lack of adverse outcomes is that large pictorial warnings with shocking pictures are typically accompanied by supportive messages designed to increase selfefficacy for quitting smoking, as well as concrete information on quitting, such as a telephone helpline number. Health communication theories, such as the Extended Parallel Process Model, predict that messages that combine threatening information with information that increase self-efficacy for behaviour change are most likely to result in positive behaviour change. ${ }^{105}$

\section{Effectiveness of health warnings among subpopulations}

Levels of perceived effectiveness have been found to be lower among dependent and more 'committed' smokers. ${ }^{37}$ However, an EU survey found that younger respondents, less-educated respondents and 'manual' workers across all groups were slightly more likely to perceive health warnings as effective. ${ }^{17}$ SES differences are likely to be most pronounced for text-only health warnings. Text-based warnings require adequate literacy skills and the literacy level of warnings in many countries is advanced. ${ }^{108} 109$ This is particularly important considering that, in most countries, smokers report lower levels of education than the general public. Picture-based warnings may be particularly important in communicating health information to populations with lower literacy rates. ${ }^{108} 110$ Preliminary evidence suggests that countries with pictorial warnings demonstrate fewer disparities in health knowledge across educational levels. ${ }^{111}$

\section{'Wear-out' and impact of health warnings over time}

Health warnings that are new or periodically updated are likely to have greater impact than 'older' warnings, even in the absence of changes in size and position. Canadian research monitored the effectiveness of the pictorial warnings among nationally representative samples over 12 waves of data collection and indicated that health warnings have their greatest impact shortly after implementation and decline in effectiveness over time. ${ }^{15}$ This is consistent with national survey data from other countries, including the UK and Australia. ${ }^{22} 3968$ In particular, youth commonly report on the stale or ineffective nature of 'old' warnings that remain unchanged for more than several years. ${ }^{18} 58115$ This is consistent with the basic principles of advertising and health communications, which suggest that the salience of a communication is greatest upon initial exposure and erodes thereafter. ${ }^{113} 114$ Although all warnings are subject to 'wear-out' over time, recent research suggests that larger pictorial warnings sustain their effects longer. ${ }^{72}$

\section{Health warnings and brand appeal}

Prominent health warnings that cover a significant proportion of the package-particularly pictorial warnings-have the potential to undermine a brand's appeal and the impact of package displays at retail outlets. ${ }^{21} 2537545664115116$ For example, 88\% of youth smokers in Canada and $90 \%$ of 'potential smokers' reported that picture-based health warnings make smoking seem less attractive. One recent study found that including graphic pictures compared with text warnings lowered the appeal of non-combustible products, nicotine lozenges and cigarettes with modified designs. ${ }^{112}$

Impact of 'standardised' or 'plain' packaging on health warnings Three studies have examined the impact of removing the colour and brand imagery from packs on the effectiveness of health warnings. When shown health warnings on 'plain' white packages with a standard colour and font size, youth in Canada ${ }^{117}$ and New Zealand ${ }^{118}$ were significantly more likely to recall specific health warnings on packs. A survey in Ontario, Canada also found that more than half of school children rated health warnings on plain white packs as 'easier to see' and 'more serious' compared with warnings on regular branded packs, with improved recall among smokers. ${ }^{33}$

\section{Credibility and public support for health warnings}

Research indicates that both adult and youth smokers report graphic warnings to be a credible source of information. $^{14-16} 182124119120$ For example, 6 years after the implementation of pictorial warnings in Canada, $86 \%$ of adult smokers and $92 \%$ of youth smokers agreed that the warnings were accurate. $^{15} 21$ Similarly, more than $90 \%$ of Australian smokers reported that large pictorial health warnings were 'believable', a slight increase from the levels reported in 2000 when text warnings appeared on Australian packages. ${ }^{24}$

Several studies also report high levels of public support for graphic pictorial warnings. ${ }^{69} 121$ In Brazil, a national survey indicated that $76 \%$ of those interviewed approved of the measure, including $73 \%$ of smokers. ${ }^{25}$ Two years after the introduction of large pictorial warnings in Uruguay, only $8 \%$ of adult smokers reported they would prefer less health information to appear on packages, whereas $62 \%$ reported they would like more health information on packages. ${ }^{26}$ Similar levels of popular support have been observed following the introduction of pictorial warnings in Canada and Thailand. ${ }^{23}{ }^{26}$ In Australia, the vast majority (85\%) of Australians considered it 'very' or 'quite important' that the government has health warnings on packs after the introduction of pictorial health warnings, including a majority of smokers. ${ }^{24}$ A significantly greater proportion of smokers and recent quitters rated health warnings as important compared with a similar survey conducted in 2000 when text warnings appeared on Australian packages. ${ }^{12}$ Finally, surveys conducted in EU member states in 2008 found that more than half of EU citizens supported the effectiveness of adding a picture to text-only health warnings, while more than $87 \%$ of respondents in a nationally representative survey in Russia agreed that graphic warnings should be mandated on packages, including $80 \%$ of smokers. ${ }^{17}{ }^{74}$ Similar levels of support have been recorded among youth. ${ }^{74}$ For example, in Canada more than $90 \%$ of youth agreed that picture warnings on Canadian packages have provided them with important information about the health effects of smoking cigarettes. ${ }^{21}$

\section{Health warnings on 'non-cigarette' tobacco products}

Labelling requirements for manufactured cigarettes are more advanced than for other tobacco products. In many jurisdictions, tobacco products such as cigars and smokeless products are subject to different regulations and often carry a different set of health warnings or no warning at all. The research literature on the effectiveness of health warnings on non-cigarette warnings is sparse. To our knowledge, only two published studies exist. 
One study found that small text warnings are likely to have little impact on recall and intentions to use smokeless tobacco among US youth. ${ }^{115}$ The second study was conducted among young adult cigarette smokers in Canada and found that pictorial health warnings increased the perceived risks of smokeless products and lowered intentions to try smokeless products. ${ }^{122}$ There is also a need for research to examine issues such as unconventional packaging sizes, which are more common for non-cigarette products. In addition, in many jurisdictions tobacco products are sold without any manufactured packaging. This practice will inevitably reduce the impact of comprehensive labelling policies. Finally, alternative tobacco products may require unique message content to reflect differences in health effects and patterns of use. ${ }^{123} 124$ Given the lack of information in this area, research on health warnings for 'alternative' tobacco products should be regarded as a priority for future work.

\section{DISCUSSION}

Health warnings on cigarette packages have a broad population reach and represent a direct means of communicating the risks of smoking. For example, 3 out of 10 participants in an EU-wide survey-equivalent to more than 160 million individualsrecently reported that health warnings on tobacco packs are effective in informing them about the health effects of tobacco. $^{17}$

The evidence also suggests that health warnings can promote smoking cessation and discourage youth uptake. Considerable proportions of smokers report that warning labels increase their motivation to quit and help them to sustain abstinence after quitting, and the use of effective cessation services increases after new health warnings have been implemented (figure 4). However, the impact of health warning labels depends upon their design: obscure text-only warnings appear to have little

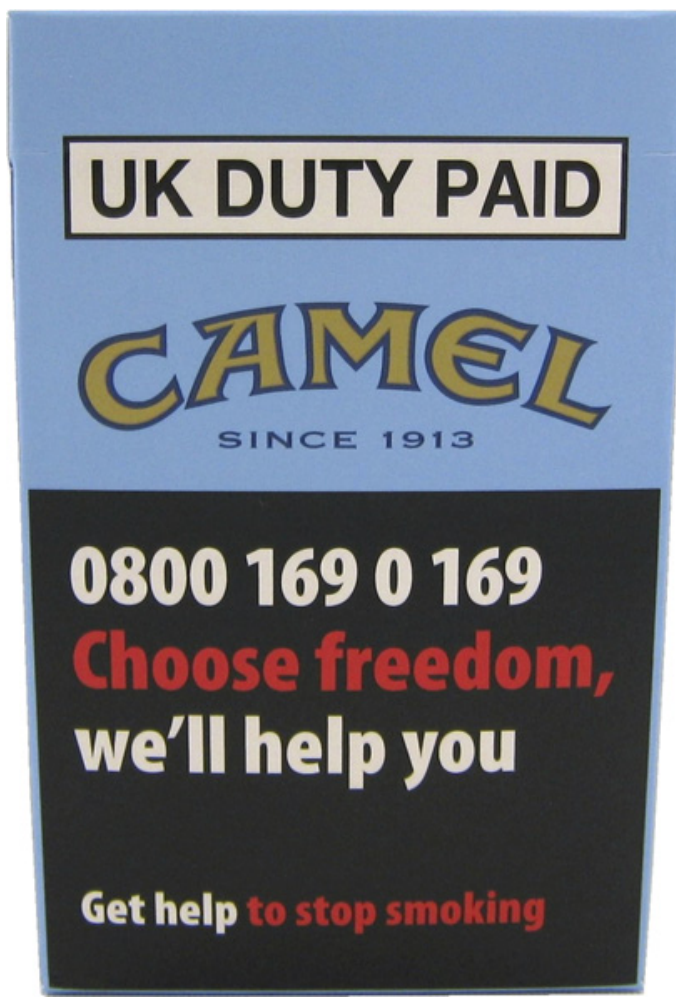

Figure 4 An example of supportive, cessation-oriented messages in the UK (2010). impact, in contrast to larger pictorial warnings on the front and back of packages in other jurisdictions. Pictorial warnings that include vivid fear-arousing depictions of health effects appear to be particularly effective among smokers and non-smokers. This finding is consistent with research evaluating anti-tobacco television ads, which indicates that messages with 'visceral negative' themes had the strongest and most consistent effects on appraisal, recall and level of engagement. ${ }^{125}{ }^{126}$ Preliminary evidence also suggests that the use of narratives or 'personal testimonials', such as a first-person account of the health effects of smoking, may be an effective theme for warnings. This is consistent with the health communication literature, which suggests that narrative evidence may be less affected by 'defensive' reactions, perhaps due to greater credibility and levels of engagement. ${ }^{127} 128$ Narrative evidence may also help individuals imagine health consequences, which may be particularly important for negative or loss-framed messages. ${ }^{129}$ Fear-arousing information and graphic images should also be integrated with efficacy information on the benefits of quitting and concrete information on ways to quit. Inclusion of concrete quitting information is strongly supported by smokers and has been shown to increase the use of these services dramatically.

Although the research literature unequivocally demonstrates the impact of comprehensive health warnings, the evidence also highlights the importance of contextual factors. Levels of effectiveness differ across countries, even for very similar health warnings. Indeed, the same text warnings have been implemented in virtually all EU member states since 2003; yet, smokers and non-smokers in different countries report different levels of effectiveness. Social norms surrounding tobacco use, as well as the strength of other tobacco control measures, likely mediate the impact of warnings. Individual-level differences, such as level of dependence, pre-existing health beliefs, and personal experience with the health effects of smoking may also mediate the impact of health warnings. In addition, not all messages resonate equally well with all individuals or target groups. ${ }^{130}$ Regulations that require a larger number of warnings to rotate on packages, such as the 16 warnings required under Canadian regulations implemented in 2001, allow for greater targeting of subgroups. Nevertheless, many messages have been found to have broad appeal and the messages found to be most effective among adults are typically rated equally well among youth and young adults. ${ }^{1518586267}$ While this evidence does not argue against the potential benefit of targeting subgroups of smokers, it does suggest that warnings do not necessarily have to be youth or adult focused to have impact.

Evidence of the benefit of using pictures and the importance of location and other design elements is consistent with evidence from other domains such as hazardous chemicals, ${ }^{50} 131$ nutritional labelling ${ }^{132} 133$ and alcohol labelling. ${ }^{134} 135$ However, the research literature indicates greater levels of impact for cigarette health warnings compared with warnings on food and alcohol products. This is likely due to differences in the design of warnings: cigarette health warnings in many jurisdictions are considerably more prominent than food and alcohol warnings in terms of their size, position on packages and the use of pictures. Indeed, evidence on the impact of obscure text-only warnings on cigarette packages is similar to the level of effectiveness associated with alcohol warning labels, for example.

Future research on tobacco health warnings should consider effective types of message content for pictorial warnings to a greater extent. There is a particular need to evaluate different themes or 'executional styles', including the potential impact of 
testimonials and personal narratives, as well as messages on the broader consequences of tobacco use, including the financial cost of smoking. It is also unclear whether the impact of messages varies across different cultures and geographical regions, particularly in low- and middle-income countries. Many low- and middle-income countries have implemented images designed for warnings in Canada and Australia. It is critical to ensure that these messages are culturally appropriate and are effective in much different cultural and social environments. Additional research is also required on implementation issues, including the ideal rotation period for 'revising' health warnings, as well as the extent to which regulations can be applied to tobacco packages with unorthodox shapes. Finally, research should examine other ways to increase the effectiveness of health warnings, such as the use of 'plain' or 'standardised' packaging, as well as novel uses of the pack, such as the use of inserts or 'onserts' attached to the outside of packs, which are commonly used by the industry for promotional purposes. ${ }^{11}$

\section{Limitations}

The research included in this review consists of a wide range of study designs conducted in diverse cultural and geographic settings. As a consequence, there are constraints on subjecting this evidence to systematic inclusion criteria based on methodology. For example, focus groups and pre-market testing conducted on behalf of governments constitute a large and important source of evidence on the impact of cigarette health warnings; yet, qualitative studies present challenges to systematic reviews, particularly when placed alongside experimental and population-based research. However, we believe that the heterogeneous nature of the research literature is an asset rather than a limitation of this evidence base, particularly considering the consistent findings across methodologies. Another limitation of the current review is that, despite the relatively broad inclusion criteria, relevant studies may have been missed, particularly studies from low- and middle-income countries that may not be widely disseminated in English.

\section{Summary}

In many ways, health warnings on tobacco packages are an ideal population-level intervention: they have broad reach, they cost little to implement and are sustainable over time. Indeed, the WHO recently identified comprehensive health warnings on packages among the six key measures required to address the global tobacco epidemic. ${ }^{2}$ Research to date highlights the importance of packaging as a medium for communicating with smokers and provides strong support for two key precedents set within the last decade: the use of pictures and the increasing size of warnings on the pack. The next generation of labelling policies and research is likely to focus on message content to a greater extent. To date, content has been relatively 'static': stand-alone messages focused primarily on health effects. However, more sophisticated message campaigns are possible, including greater linkages across individual messages, building narratives over time, and using packages to link smokers with cessation services. Countries such as Australia have taken the first step towards integrating health warnings with mass media campaigns. As these regulatory developments unfold, research must keep pace to ensure that the evidence base evolves in parallel with regulatory practice.

Acknowledgements I thank Samantha Daniel and Jessica Reid for assisting with the preparation of the manuscript, including reviewing the paper for methodological quality and preparing the brief summaries.
Funding This paper was supported by the Propel Centre for Population Health Impact at the University of Waterloo and a Canadian Institutes of Health New Investigator Salary Award.

Competing interests None.

Contributors David Hammond is the sole author of this work.

Provenance and peer review Not commissioned; externally peer reviewed.

\section{REFERENCES}

1. World Health Organization. Tobacco Free Initiative. Information on Global Tobacco Use. http://www.who.int/tobacco/health_priority/en/index.html laccessed 14 Jul 2009).

2. WHO Report on the Global Tobacco Epidemic, 2008. Geneva: World Health Organization, 2008. http://www.who.int/tobacco/mpower/en laccessed $12 \mathrm{Apr}$ 2010).

3. US Department of Health and Human Services. The Health Consequences of Smoking: A Report of the Surgeon General. Atlanta, Georgia: Dept of Health and Human Services, Centers for Disease Control and Prevention, National Center for Chronic Disease Prevention and Health Promotion, Office on Smoking and Health: Washington, DC, 2004

4. Slade J. The pack as advertisement. Tob Control 1997:6:169-70.

5. Wakefield M, Morley C, Horan JK, et al. The cigarette pack as image: new evidence from tobacco industry documents. Tob Control 2002;11(Suppl 1):173-80.

6. Pollay RW. The Role of Packaging Seen Through Industry Documents. Expert Report prepared for: JTI-Macdonald., Imperial Tobacco Canada Ltd and Rothmans, Benson \& Hedges Inc. v. Attorney General of Canada and Canadian Cancer Society (intervenor). Supreme Court, Province of Quebec, District of Montreal, 2001. Defense Exhibit D-116.

7. Dewhirst T. POP goes the power wall? Taking aim at tobacco promotional strategies utilised at retail. Tob Control 2004;13:209-10.

8. World Health Organization. WHO Framework Convention on Tobacco Control. Geneva: World Health Organization, 2003. http://www.who.int/tobacco/framework/ en (accessed 12 Apr 2010)

9. WHO Framework Convention on Tobacco Control. Elaboration of Guidelines for Implementation of Article 11 of the Convention, 2008. http://apps.who.int/gb/fctc/ PDF/cop3/FCTC_COP3_7-en.pdf.

10. Aftab M, Kolben D, Lurie P. International cigarette labeling practices. Tob Control 1999:8:368-72.

11. Hammond D. Tobacco Labeling Resource. Waterloo, ON. http://www tobaccolabels.org (accessed 12 Apr 2010).

12. Fathelrahman Al, Omar M, Awang R, et al. Smokers' responses towards cigarette pack warning labels in predicting quit intention, stage of change, and self-efficacy. Nicotine Tob Res 2009;11:248-53.

13. Elliott \& Shanahan Research. Evaluation of the Health Warnings and Explanatory Health Messages on Tobacco Products. Canberra: Department of Health and Aged Care, 2000. http://www.health.gov.au/internet/main/publishing.nst/Content/ 474DA5DAC70608F2CA2571A1001C7DFE/\$File/execsumm.pdf laccessed 12 Apr 2010).

14. Chaiton M, Cohen J, Kaiserman MJ, et al. Beliefs and Attitudes. In: 2002 Youth Smoking Survey-Technical Report. Health Canada, 2004. http://www.hc-sc.gc.ca/ hc-ps/pubs/tobac-tabac/yss-etj-2002/index-eng.php (accessed 12 Apr 2010).

15. Environics Research Group. The Health Effects of Tobacco and Health Warning Messages on Cigarette Packages - Survey of Adults and Adults Smokers: Wave 12 Surveys. Prepared for Health Canada. Toronto, Canada: Environics Research Group 2007

16. Moodie C, Mackintosh AM, Hammond D. Adolescents' response to text-only tobacco health warnings: Results from the 2008 UK Youth Tobacco Policy Survey. Eur J Public Health 2010;20:463-9.

17. European Commission. Eurobarometer: Survey on Tobacco (Analytical Report). 2009. http://ec.europa.eu/public_opinion/flash/fl_253 en.pdf (accessed 12 Apr 2010)

18. Environics Research Group. Canadian Adult and Youth Opinions on the Sizing of Health Warning Messages. Environics Research Group Limited, 1999. http://dsppsd.pwgsc.gc.ca/Collection/H49-134-1999E.pdf (accessed 12 Apr 2010)

19. Les Études De Marche Createc. Ouantitative Study of Canadian Youth Smokers and Vulnerable Non Smokers: Effects of Modified Packaging Through Increasing the Size of Warnings on Cigarette Packages. Prepared for Health Canada. 2008. http:// www.tobaccolabels.ca/healt/canada2008 3 (accessed 12 Apr 2010).

20. Les Études de Marche Createc. Quantitative Study of Canadian Adult Smokers: Effects of Modified Packaging Through Increasing the Size of Warnings on Cigarette Packages, 2008. Health Canada, (accessed 5 Jan 2008). http://www tobaccolabels.ca/healt/canada $\sim 7$ (accessed 12 Apr 2010).

21. Environics Research Group. The Health Effects of Tobacco and Health Warning Messages on Cigarette Packages - Survey of Youth: Wave 12 Surveys. Prepared for Health Canada. 2007

22. Borland R, Hill D. Initial impact of the new Australian tobacco health warnings on knowledge and beliefs. Tob Control 1997:6:317-25.

23. Hammond D, Fong GT, McDonald $\mathrm{P}$, et al. Impact of the graphic Canadian warning labels on adult smoking behaviour. Tob Control 2003:12:391-5.

24. Shanahan $\mathbf{P}$, Elliott D. Evaluation of the Effectiveness of the Graphic Health Warnings on Tobacco Product Packaging 2008. Canberra: Australian Government 
Department of Health and Ageing, 2009. http://www.health.gov.au/internet/main/ publishing.nsf/Content/health-pubhlth-strateg-drugs-tobacco-warnings.htm (accessed 12 Apr 2010)

25. Cavalcante TM. Labelling and Packaging in Brazil. National Cancer Institute, Health Ministry of Brazil; World Health Organization. http://www.who.int/tobacco/ training/success stories/en/best practices brazil labelling.pdf laccessed $12 \mathrm{Apr}$ 2010).

26. International Tobacco Control Policy Evaluation Project. FCTC Article 11-Tobacco Warning Labels: Evidence and Recommendations from the ITC Project. 2009. http://www.itcproject.org (accessed 22 Jun 2009).

27. Hammond D, Fong GT, Borland R, et al. Effectiveness of cigarette warning labels in informing smokers about the risks of smoking: findings from the International Tobacco Control (ITC) Four Country Survey. Tob Control 2006;15(Suppl III):iii19-25.

28. Crawford MA, Balch Gl, Mermelstein R, et al. Responses to tobacco control policies among youth. Tob Control 2002;11:14-19.

29. Fischer PM, Richards EJB, Krugman DM. Recall and eye tracking study of adolescents viewing tobacco advertisements. JAMA 1989;261:84-9.

30. BRC Marketing \& Social Research. Smoking Health Warnings Stage 2: Optimising Smoking Health Warnings-Text Graphics, Size, and Colour Testing. Prepared for the New Zealand Ministry of Health, 2004. http://www.ndp.govt.nz/ moh.nsf/indexcm/ndp-publications-smokinghealthwarningsstage2aug2004 (accessed 12 Jul 2009)

31. Centre for Behavioural Research in Cancer, ACCV. Health Warnings and Contents Labelling on Tobacco Products. Centre for Behavioural Research in Cancer, 1992.

32. Linthwaite P. Health warnings. Health Educ J 1985:44:218-19.

33. Rootman I, Flay BR. A Study on Youth Smoking: Cigarette Packaging and Event Marketing Increases the Attractiveness of Smoking. Toronto, ON: University of Toronto, 1995. http://www.tobaccolabels.ca/prohibit/canadaandu (accessed 12 Apr 2010).

34. Teeboom Y. Waarschuwende teksten op sigarettenpakjes, 2002. http://www. stivoro.nl/upload/_ publdocs/o w2002 jeugd.pdf (accessed 12 Apr 2010).

35. Nilsson T. Legibility of Tobacco Health Messages with Respect to Distance. A Report to the Tobacco Products Division of the Health Protection Branch of Health and Welfare Canada, 1991. http://dsp-psd.pwgsc.gc.ca/Collection/H49-132-1999E. pdf (accessed 12 Apr 2009)

36. Tandemar Research Inc. Cigarette Packaging Study: The Evaluation of New Health Warning Messages. Toronto, ON: Tandemar Research Inc., 1996.

37. Devlin E, Anderson S, Hastings G, et al. Targeting smokers with tobacco warning labels - opportunities and challenges for Pan European health promotion. Health Promot Int 2005;20:41-9.

38. Fong GT, Ratte $\mathrm{S}$, Craig $\mathrm{L}$, et al. Évaluation des politiques de lutte contre le tabagisme en France: résultats de la première vague de l'enquête ITC France. Evaluating tobacco control policies in France: Results of the first wave of the ITC France Survey. Bulletin Épidémiologique Hebdomadaire (Numéro thématique-Journée mondiale sans tabac 2008. Weekly Epidemiological Bulletin (Special Issue-World No Tobacco Day 2008) 2007:22:183-7.

39. Borland R, Yong HH, Wilson $\mathrm{N}$, et al. How reaction to cigarette packet health warnings influence quitting: findings from the ITC Four Country survey. Addiction 2009; 104:669-75.

40. Portillo F, Antonanzas F. Information disclosure and smoking risk perceptions: potential short-term impact on Spanish students of the new European Union directive on tobacco products. Eur J Public Health 2002;12:295-301.

41. IPSOS survey, Belgium. Effectiveness of picture warnings on behalf of the Belgium Cancer Foundation, 2007

42. Strahan EJ, White K, Fong GT, et al. Enhancing the effectiveness of tobacco package warning labels: a social psychological perspective. Tob Control 2002;11:183-90

43. Levie WH, Lentz R. Effects of text illustrations: a review of research. Educ Comm Technol J 1982; 30:195-232.

44. Braun CC, Kline PB, Silver NC. The influence of colour on warning label perceptions. Int J Ind Ergon 1995:15:179-87.

45. Sherman SJ, Cialdini RB, Schwartzman DF, et al. Imagining can heighten or lower the perceived likelihood of contracting a disease: the mediating effect of ease of imagery. Pers Soc Psychol Bull 1985;11:118-27.

46. Leventhal $\mathbf{H}$. Findings and theory in the study of fear communications. In: Berkowitz L, ed. Advances in Experimental Social Psychology. Vol. 5. New York: Academic Press, 1970:119-86.

47. Dewar RE. Design and evaluation of public information symbols. In: Zwaga HJG, Boersma T, Hoonhout HCM, eds. Visual Information for Everyday Use: Design and Research Perspectives. London: Taylor and Francis, 1999:285-303.

48. Kalsher MJ, Wogalter MS, Racicot BM. Pharmaceutical container labels and warnings: Preference and perceived readability of alternative designs and pictorials. Int J Indus Ergon 1996;18:83-90.

49. Leonard SD, Otani H, Wogalter MS. Comprehension and memory. In: Wogalter MS, DeJoy DM, Laughery KR, eds. Warnings and Risk Communication. London: Taylor and Francis, 1999:149-87.

50. Winder C, Azzi R, Wagner D. The development of the globally harmonized system (GHS) of classification and labelling of hazardous chemicals. J Hazard Mater 2000; 125:29-44

51. Liefeld JP. The Relative Importance of the Size, Content and Pictures on Cigarette Package Warning Messages. Prepared for Health Canada. Guelph, Canada Department of Consumer Studies, University of Guelph, 1999.
52. O'Hegarty M, Pederson LL, Nelson DE, et al. Reactions of young adult smokers to warning labels on cigarette packages. Am J Prev Med 2006; 30:467-73.

53. Vardavas Cl, Connolly G, Karamanolis K, et al. Adolescents perceived effectiveness of the proposed European graphic tobacco warning labels. Eur $J$ Public Health 2009:19:212-17.

54. Kees J, Burton S, Andrews JC, et al. Tests of graphic visuals and cigarette package warning combinations: implications for the framework convention on tobacco control. J Public Policy Marketing 2006:25:212-23.

55. Kees J, Burton S, Andrews JC, et al. Understanding how graphic pictorial warnings work on cigarette packaging. J Public Policy Marketing 2010;29:115-26.

56. Sabbane LI, Bellavance F, Chebat JC. Recency versus repetition priming effects of cigarette warnings on nonsmoking teenagers: the moderating effects of cigarettebrand familiarity. J App/ Soc Psychol 2009;39:656-82

57. Fong GT, Hammond D, Yuan J, et al. Perceptions of Tobacco Health Warnings in China Compared to Picture and Text-Only Health Warnings From Other Countries: An Experimental Study. Tob Control 2010:19(Suppl 2):i69-i77.

58. Environics Research Group. Testing New Health Warning Messages for Cigarette packages: A Summary of Three Phases of Focus Group Research: Final Report. Prepared for Health Canada, 2000. http://www.tobaccolabels.ca/healt/canada (accessed 12 Jul 2009).

59. Corporate Research Associates. Creative Concept Testing for Health Warning Messages. Prepared for Health Canada, 2005. http://www.tobaccolabels.ca/healt/ canada2005 (accessed 13 Jul 2009)

60. Clemenger BBDO. Marketing Inputs to Assist the Development of Health Warnings for Tobacco Packaging. Report to the Ministry of Health: Review of the Smoke-free Environments Regulations, 2004. http://www.ndp.govt.nz/moh.nsf/indexcm/ndppublications-marketinginputsmay2006 (accessed 13 Jul 2009).

61. BRC Marketing \& Social Research. Smoking Health Warnings Stage 1: The Effectiveness of Different (Pictorial) Health Warnings in Helping People Consider their Smoking-Related Behaviour. Prepared for the New Zealand Ministry of Health, 2004.

62. Elliott \& Shanahan (E\&S) Research. Developmental Research for New Australian Health Warnings on Tobacco Products: Stage 1. Prepared for the Population Health Division Department of Health and Ageing. Commonwealth of Australia, 2002. http://www.health.gov.au/internet/main/publishing.nst/Content/

474DA5DAC70608F2CA2571A1001C7DFE/\$File/warnings stage1.pdf (accessed 13 Jul 2009)

63. Elliott \& Shanahan (E\&S) Research. Developmental Research for New Australian Health Warnings on Tobacco Products Stage 2. Prepared for: The Australian Population Health Division Department of Health and Ageing. Commonwealth of Australia, 2003. http://www.tobaccolabels.ca/healt/australia2 laccessed $13 \mathrm{Jul}$ 2009).

64. Gallopel-Morvan K, Gabriel P, Le Gall-Ely M, et al. The use of visual warnings in social marketing: The case of tobacco. Journal of Business Research 2011:64:7-11.

65. UK Department of Health. Consultation on the Introduction of Picture Warnings on Tobacco Packs: Report on Consultation, 2007. http://www.dh.gov.uk/en/ Consultations/Responsestoconsultations/DH_077960 (accessed 13 Jul 2009).

66. Ministry of Health, Bulgaria. Most effective pictures out of 42 images - web based survey. Ministry of Health, 2008

67. Les Etudes de Marche Createc. Final Report: Qualitative Testing of Health Warnings Messages. Prepared for the Tobacco Control Programme Health Canada. 2006

68. Hammond D, Fong GT, Borland R, et al. Text and Graphic Warnings on Cigarette Packages: Findings from the ITC Four Country Survey. Am J Prev Med 2007:32:202-9.

69. Hammond D, Fong GT, McDonald P, et al. Graphic Canadian warning labels and adverse outcomes: evidence from Canadian smokers. Am J Public Health 2004; $94: 1442-5$.

70. Thrasher JF, Hammond D, Fong GT. Smokers' reactions to cigarette package warnings with graphic imagery and with only text: a comparison between Mexico and Canada. Salud Publica Mex 2007;49(Suppl 2):S233-40.

71. White V, Webster B, Wakefield M. Do graphic health warning labels have an impact on adolescents' smoking related beliefs and behaviours? Addiction 2008; 103:1562-71.

72. Borland R, Wilson N, Fong GT, et al. Impact of graphic and text warnings on cigarette packs: findings from four countries over five years. Tob Control 2009; 18:358-64.

73. Hassan LM, Shiu E, Thrasher JF, et al. Exploring the effectiveness of cigarette warning labels: findings from the United States and United Kingdom arms of the International Tobacco Control (ITC) Four Country Survey. Int J Nonprofit Volunt Sect Mark 2008:13:263-74.

74. Wade B, Merrill RM, Lindsay GB. Cigarette pack warning labels in Russia: how graphic should they be? Eur J Public Health Published Online First: 21 July 2010 doi:10.1093/eurpub/ckq098.

75. Petersen LE, Lieder F. Die Effektivität von schriftlichen und graphischen Warnhinweisen auf Zigarettenschachteln: Eine Überprüfung des revidierten Modells der Schutzmotivation. Zeitschrift für Sozialpsychologie 2006:37:245-58.

76. Sabbane LI, Lowrey TM, Chebat JC. The effectiveness of cigarette warning labe threats on nonsmoking adolescents. J Consumer Affairs 2009:43:332-5.

77. Gygax PM, Bosson M, Gay C, et al. Relevance of health warnings on cigarette packs: a psycholinguistic investigation. Health Commun 2010;25:397-409. 
78. International Agency for Research on Cancer (IARC). IARC Handbooks of Cancer Prevention: Tobacco Control. Volume 12. Methods for Evaluating Tobacco Control Policies. Lyon, France: International Agency for Research on Cancer. http:// apps.who.int/bookorders/anglais/detart1.jsp?

sesslan=1\&codlan=1\&codcol=76\&codcch =28 (accessed 13 Jul 2009)

79. Willemsen MC. The new EU cigarette health warnings benefit smokers who want to quit the habit: results from the Dutch Continuous Survey of Smoking Habits. Eur J Public Health 2005;15:389-92.

80. Canadian Cancer Society Evaluation of New Warnings on Cigarette Packages. Prepared by: Environics, Focus Canada 2001-3, 2001. http://www.cancer.ca/ / media/CCS/Canada\%20wide/Files\%20List/English\%20files\%20heading/pdf\%20not\% 20in\%20publications\%20section/Environics\%20study\%20on\%20cigarette\% 20warning\%20labels\%20-\%20complete.ashx (accessed 13 Jul 2009).

81. Hill D. New cigarette-packet warnings: are they getting through? Med J Aust 1988:148:478-80.

82. Koval JJ, Aubut JA, Pederson LL, et al. The potential effectiveness of warning labels on cigarette packages: the perceptions of young adult Canadians. Can $J$ Public Health 2005;96:353-6.

83. UK Department of Health. Consultation on the Introduction of Picture Warnings on Tobacco Pack, 2006. http://www.dh.gov.uk/assetRoot/04/13/54/96/04135496.pdf.

84. Willemsen MC, Simons C, Zeeman G. Impact of the new EU health warnings on the Dutch quit line. Tob Control 2002;11:382.

85. Miller CL, Hill DJ, Quester PG, et al. Impact on the Australian Quitline of new graphic cigarette pack warnings including the Quitline number. Tob Control 2009;18:228-34.

86. Wilson N, Li J, Hoek J, et al. Long-term benefit of increasing the prominence of a quitline number on cigarette packaging: 3 years of Quitline call data. N Z Med J 2010;123:109-11.

87. Hammond D, McDonald PW, Fong GT, et al. Cigarette warning labels, smoking bans, and motivation to quit smoking: evidence from former smokers. Can J Public Health 2004:95:201-4.

88. Gospodinov N, Irvine I. Global health warnings on tobacco packaging: evidence from the Canadian experiment. Top Econ Anal Pol 2004;4:30.

89. Health Canada. Canadian Tobacco Use Monitoring Survey (CTUMS). http://www. hc-sc.gc.ca/hc-ps/tobac-tabac/research-recherche/stat/ctums-esutc_2008-eng.php (accessed 13 Jul 2009).

90. Flay BR, Burton D. In: Atkin C, Wallack L, eds. Mass Communication for Public Health. Newbury Park, CA: Sage Publications, 1990:129-46.

91. Sweet KM, Willis SK, Ashida S, et al. Use of fear-appeal techniques in the design of tailored cancer risk communication messages: implications for healthcare providers. J Clin Oncol 2003;21:3375-6.

92. Peters $\mathbf{E}$, Romer D, Slovic $\mathrm{P}$, et al. The impact and acceptability of Canadian-style cigarette warning labels among U.S. smokers and nonsmokers. Nicotine Tob Res 2007; 9:473-81.

93. Rozin P, Haidt J, McCauley CR. Disgust. In: Lewis M, Haviland-Jones JM, eds, Handbook of emotions, 2nd edn. New York: Guilford Press, 2000:637-53.

94. Dillard JP, Pfau M. The Persuasion Handbook: Developments in Theory and Practice. Thousand Oaks, CA: Sage Publications, 2002.

95. Donovan RJ, Jalleh G, Carter OBJ. Tobacco industry smoking prevention advertisements; impact on youth motivation for smoking in the future. Soc Marketing 0 2006; 7:3-13

96. Nascimento BEM, Oliveira L, Vieira AS, et al. Avoidance of smoking: the impact of warning in Brazil. Tob Control 2008:17:405-9.

97. Hammond D, Thrasher JF, Reid J. Mexico Health Warning Study: International Packaging Study, 2010. http://davidhammond.ca/downloads/Mexico\%20Packaging \%20Study/ (accessed 20 Jan 2010).

98. Western Opinion/NRG Research Group. Illustration-Based Health Information Messages: Concept Testing. Prepared for Health Canada, 2006. http://www. tobaccolabels.ca/healt/canada2006 (accessed 12 Apr 2010)

99. Decima Research Testing of Health Warning Messages and Health Information Messages for Tobacco Products Executive Summary. Prepared on behalf of Health Canada, 2009.

100. Goodall C, Appiah 0. Adolescents' perceptions of Canadian cigarette package warning labels: investigating the effects of message framing. Health Commun 2008;23:117-27.

101. Hastings G, MacFadyen L. Controversies in tobacco control: the limitations of fear messages. Tob Control 2002;11:73-5

102. Biener L, Taylor TM. The continuing importance of emotion in tobacco control media campaigns: a response to Hastings and MacFadyen. Tob Control 2002;11:75-7.

103. Ruiter RAC. Saying is not (always) doing: cigarette warning labels are useless. Eur J Public Health 2005:15:329-30.

104. Ruiter RAC, Abraham C, Kok G. Scaring warnings and rational precautions: a review of the psychology of fear appeals. Psychol Health 2001;16:613-30.

105. Witte K, Allen M. A meta-analysis of fear appeals: implications for effective public health campaigns. Health Educ Behav 2000;27:591-615.

106. Brehm JW. A Theory of Psychological Reactance. Academic Press, 1966.
107. Robinson TN, Killen JD. Do cigarette warning labels reduce smoking? Paradoxica effects among adolescents. Arch Pediatr Adolesc Med 1997;151:267-72.

108. CRÉATEC + Market Studies. Effectiveness of Health Warning Messages on Cigarette Packages in Informing Less-literate Smokers, Final Report. Prepared for Communication Canada, 2003

109. Malouff J, Gabrilowitz D, Schutte N. Readability of health warnings on alcohol and tobacco products. Am J Public Health 1992;82:464.

110. Reid JL, Hammond D, Driezen P. Socioeconomic status and smoking in Canada, 1999-2006: Has there been any progress on disparities in tobacco use? Can J Public Health 2010;101:73-8.

111. Siahpush M, McNeill A, Hammond D, et al. Socioeconomic and country variations in knowledge of health risks of tobacco smoking and toxic constituents of smoke: results from the 2002 International Tobacco Control Policy Evaluation Survey. Tob Control 2006;15(Suppl III):iii65-70.

112. Stark E, Kim A, Miller C, et al. Effects of including a graphic warning label in advertisements for reduced-exposure products: implications for persuasion and policy. J App/ Soc Psychol 2008;38:281-93.

113. Henderson B. Wear out: an empirical investigation of advertising wear-in and wear-out. J Advert Res 2000;6:95-100.

114. Bornstein RF. Exposure and affect: overview and meta-analysis of research. Psychol Bull 1989;106:265-89.

115. Brubaker RG, Mitby SK. Health-risk warning labels on smokeless tobacco products: are they effective? Addict Behav 1990:15:115-18.

116. Thrasher JF, Rousu MC, Ocampo-Anaya R, et al. Estimating the impact of graphic warning labels on cigarette packs: the auction method. Salud Publica Mex 2006;48 (Suppl 1):S155-66.

117. Goldberg ME, Liefeld J, Madill J, et al. The effect of plain packaging on response to health warnings. Am J Public Health 1999;89:1434-5.

118. Beede $\mathbf{P}$, Lawson R. The effect of plain packages on the perception of cigarette health warnings. Public Health 1992;106:315-22.

119. Cecil H, Evans RI, Standley MA. Perceived believability among adolescents of health warning labels on cigarette packs. J App/ Soc Psychol 1996;26:502-19.

120. Angus Reid. Canadians Welcome New Graphic Warnings on Cigarette Packages 2011. http://www.angus-reid.com/wp-content/uploads/2011/01/ 2011.01.10_Tobacco_CAN.pdf (accessed 20 Jan 2011).

121. Borland R, Hill D. The path to Australia's tobacco health warnings. Addiction 1997:92:1151-7.

122. Callery WE, Hammond D, O'Connor RJ, et al. The appeal of smokeless tobacco products among young Canadian smokers: the impact of pictorial health warning and relative risk messages. Nicotine Tob Res. Published Online First: 28 February 2011 doi:10.1093/ntr/ntr013.

123. Les Etudes de Marche Createc. Health Warning Messages on Smokeless Tobacco, Cigars and Pipe Products A Qualitative Study with Consumers. Prepared for Health Canada Tobacco Control Programme, 2003.

124. Environics Research Group. Testing of Mock-ups of Health Warning Messages and Warning Notices on Tobacco Product Advertisements for Smokeless Tobacco. Prepared for Health Canada, 2007. http://www.tobaccolabels.ca/healt/ canada2007 2 (accessed 12 Apr 2010)

125. Terry-McElrath $\mathbf{Y}$, Wakefield $M$, Ruel $\mathrm{E}$, et al. The effect of antismoking advertisement executional characteristics on youth comprehension, appraisal, recall, and engagement. J Health Commun 2005;10:127-43.

126. Wakefield M, Durrant R, Terry-McElrath Y, et al. Appraisal of anti-smoking advertising by youth at risk for regular smoking: a comparative study in the United States, Australia, and Britain. Tob Control 2003;12(Suppl 2):iï2-6.

127. de Wit JBF, Das E, Vet R. What works best: objective statistics or a personal testimonial? An assessment of the persuasive effects of different types of message evidence on risk perception. Health Psychol 2008;27(1):110-15.

128. Slater MD, Rouner D. Value-affirmative and value-protective processing of alcoho education messages that include statistical evidence or anecdotes. Commun Res 1996;23:210-35.

129. Broemer $\mathbf{P}$. Ease of imagination moderates reactions to differently framed health messages. Eur J Soc Psychol 2004;34:103-19.

130. Devlin E, Eadie D, Stead M, et al. Comparative study of young people response to anti-smoking messages. Int J Advert 2007:26:99-128.

131. Sattler B, Lippy B, Jordan TG. Hazard Communication: A Review of the Science Underpinning the Art of Communication for Health and Safety. U.S. Department of Labor Occupational Safety \& Health Administration, 1997. http://www.osha.gov/ dsg/hazcom/hc2inf2.html.

132. Cowburn G, Stockley L. Consumer understanding and use of nutrition labelling: a systematic review. Public Health Nutr 2005;8:21-8.

133. Kristal AR, Levy L, Patterson RE, et al. Trends in food label use associated with new nutrition labeling regulations. Am J Public Health 1998:88:1212-15.

134. MacKinnon DP. Review of the effects of the alcohol warning label. In: Watson RR ed. Drug and Alcohol Abuse Reviews, Vol. 7: Alcohol, Cocaine, and Accidents. Totowa, NJ: Humana Press Inc, 1995:131-61.

135. MacKinnon DP, Nohre L, Pentz MA, et al. The alcohol warning and adolescents: 5-year effects. Am J Public Health 2000:90:1589-94. 